\title{
An Investigation of Neo-psychoanalytic Dream Type/ Content and Its Relationship to Personality
}

\author{
Norita Jill Bishop \\ East Tennessee State University \\ Henry Jefferson Grubb, Ph.D. \\ East Tennessee State University \\ Nancy Hamblen Acuff, Ph.D. \\ East Tennessee State University
}

\begin{abstract}
Several studies have investigated the relationship between personality variables and dream content. The evidence for a Jungian interpretation of dreaming and character logic functioning is equivocal. After a review of the literature, the authors hypothesize that there is a significant correlation between content of the dream and personality typology. The subjects of this study were students at East Tennessee State University, all enrolled in two Developmental Psychology classes (the classes were taken as an elective by the majority of the subjects with participation in the study an option of the course). A total of 49 subjects, 38 females and 11 males, were recruited during the spring academic semester, 1988 . The subjects were engaged in dream therapy for two weeks. The Pearlman Dream Technique, an Adlerean based approach, was used in the dream survey and interpretation. Subjects also completed the Myers-Briggs Type indicator, the Gordon Personal Profile Inventory, and the Jungian Archetypal Personality Inventory. Correlation analysis comparing personality types and dream content and format suggests that a more intuitive, introspective character is manifested through a more active imaginal (i.e., dream) life. More outgoing personalities were found to have less elaborate archetypical dreams. Finally, Common dreams served less of "balancing" function in people's lives than the deeper structure archetypal dreams.
\end{abstract}

\section{REVIEW}

One of Jung's major intro-psychic constructs describes the compensation concept; the notion of an impelling equilibrium between contradicting mental elements (i.e., that which is conscious is compensated by that what is unconscious) (Domino, 1976). This theme is reflected in dreams; a prevalently extroverted person will have an introverted quality to his dreams while the predicted dream life of the introverted will be expected to be extroverted (Domino, 1976).

Jung suggested that dreams were an involuntary expression of the psychic process, which is not under the control of the conscious mind. He also described two classes of dreams: (1) the archetypal, or the collective conscious representation, and; (2) the everyday dream, or the personal unconscious nocturnal manifestations. The former representing innate and inherited content while the latter being conditioned by the individual's life history (Cann and Donderi, 1986; Kluger, 1975).

H. Y. Kluger, (1975), reported that neurophysiological and REM research on dreams suggest that dreaming is dependent on primitive brain structure and on cognitive ability these findings being congruous with Jung's two types of dreams. Jung's innate collective unconscious, the 
archetypes, show instinctive patterns of behavior while the personal unconscious comes from the individual's life history. Therefore, Kluger was saying that a dream is a reflection of instinct and individual history. This is logical because the dream is the by-product of the individual's genetic and learning history.

Kluger, (1975), developed a method of scoring dreams; he ranked them into Jung's two types and according to the content, assigning numerical value to the dreams. After this coding, he used these values to statistically evaluate the dreams. Kluger's (1975) methods were employed in the present study. After a review of the literature, this research investigated the correlation between personality and dream content based on Jungian theory and Kluger's means of evaluation. Therefore, it was hypothesized that the authors would find a significant correlation between content of dreams and personality typology.

\section{Subjects}

\section{METHOD}

Subjects in this study were students enrolled in two Developmental Psychology classes at East Tennessee State University during the spring semester of academic year 1988. The classes were taken as electives by the majority of the subjects with participation in the study being optional. There was a total of 49 subjects (38 Females and 11 males). Forty-eight of the subjects were Caucasian, the one remaining being Asian-American. Mean age for the females was 20.6 with a range of 17 to 44 years and the mean age for the males was 24.8 with a range of 20 to 37 years.

\section{Instruments}

Subjects were given two personality tests; the Myers-Briggs Type Indicator (Form G) and the Gordon Personal Profile-Inventory (GPP-I, 1988 revision). The Jungian Archetypal Analysis and the Pearlman Dream Technique were also administered to the subjects. The Myers-Briggs Type Indicator was utilized because of its Jungian base and its ability to reveal personality linked perceptions of external and internal events. Preferences were the key factor in the test because of answer selection.

To gain a broader view of the subjects personality the Gordon Personal Profile-Inventory was employed. This test is a combination of 2 tests; (1) the Gordon Personal Profile, which provides a measure of four personality aspects that are significant in the daily functioning of a normal person (i.e., Ascendancy, Responsibility, Emotional Stability, and Sociability): and (2) the Gordon Personal Inventory, which measures four additional traits (i.e., Cautiousness, Original Thinking, Personal Relations, and Vigor). This personality inventory was developed independent of Jungian Theory so was expected not to be as correlated to dream types or personal and collective unconscious structures.

To rank the subjects archetypes, the Jungian Archetypal Analysis test was utilized. Finally, The Pearlman Dream Technique, an Adlerean based approach, was used the dream survey and interpretation.

\section{Procedure}

The Subjects were selected from pre-arranged Developmental Psychology Classes. Students, who participated, were told that they would be the subjects in a research project attempting to determine if there was a relationship between personality variables and dream content. The instructor for the class, one of the investigators, utilized the Pearlman Dream Technique (see Appendix A) for the dream survey and interpretation. The subjects were grouped into pairs 
and worked together on the survey. Elapsed time for this portion of the testing was one week in each class. Nightly dreams were collected, renewed and analyzed for content.

The Myers-Briggs Type Indicator (Form G) was the first personality test to be given to the subjects. Response sheets were handed out to each subject and instructions explained by the experimenter. Next, the Gordon Personal Profile-Inventory (GPP-I) was given to each volunteer and the same explanation given. Elapsed time for both personality tests were two hours in each class.

The final portion of the data collection, consisting of Jungian Archetypal Analysis (see Appendix B) took approximately one hour. H. Y. Kluger (1975) provided the format for the Pearlman Dream Technique and the Jungian Archetypal Analysis. The third author, with extensive experience in both the Pearlman Dream Technique and Jungian Archetypal Analysis did the actual coding.

\section{Experimental Design}

The types of analysis' used in our study are the Pearson correlation matrix with continuous variables, and the Chi-square with discrete variables. Finally, frequency tables were developed and are presented for review.

\section{RESULTS}

A significant relationship was discovered between the Myers-Briggs Personality types (see Appendix $\mathrm{C}$ ) and Dream Types ( $\mathrm{r}=.4515, \mathrm{p} \geq .01)$. Twenty percent our variables were accounted for here, a significant relationship was found between older and younger subjects $(\mathrm{r}=.4855$, $\mathrm{p} \geq .001$ ) (See Figure 1). 


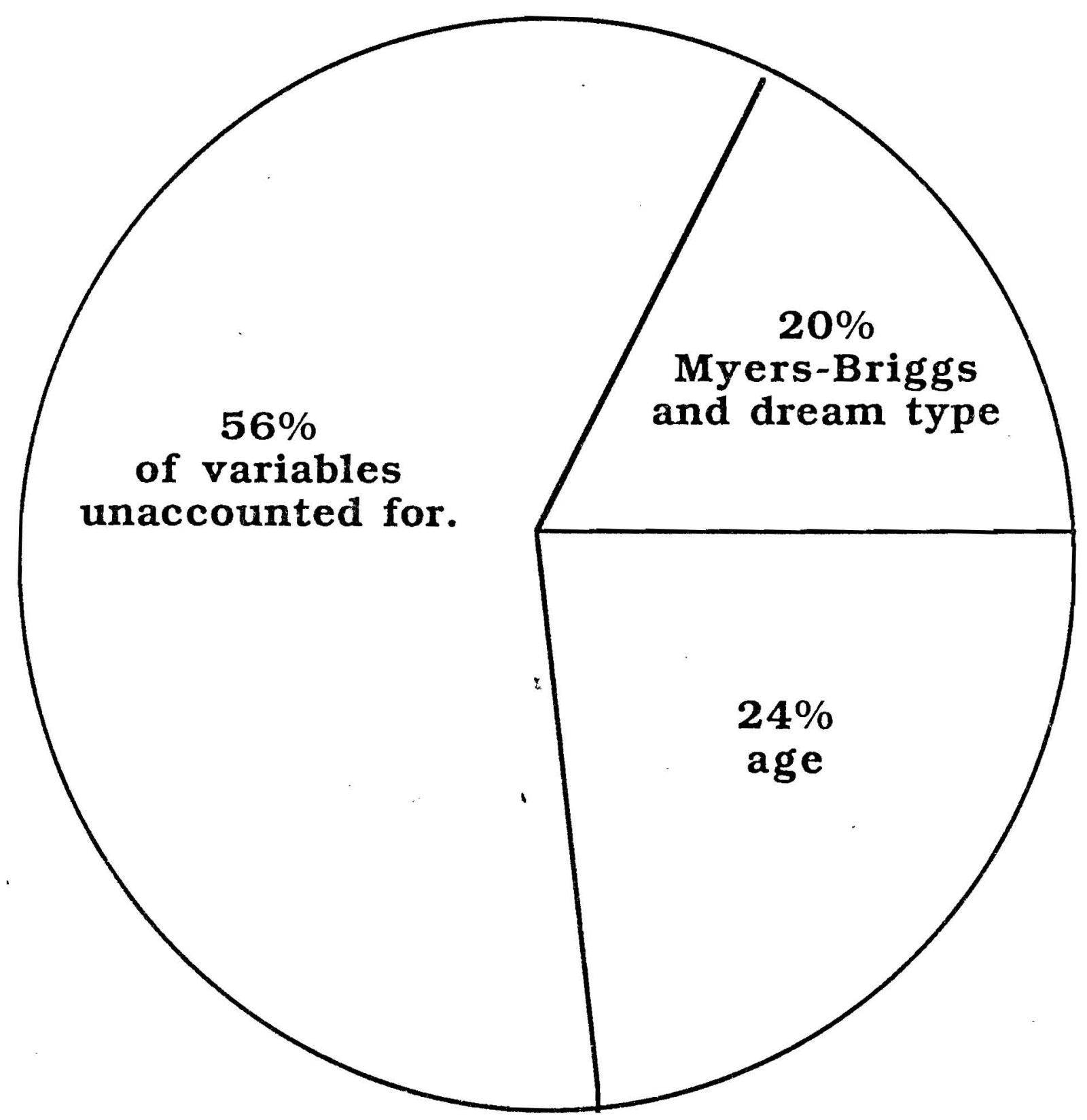

Figure 1- - The percentages of variables accounted for by the Pearson Correction Analysis.

The Chi-square statistic revealed a significant relationship between the number of dreams and dream type ( $\mathrm{p} \geq .0431)$. Also, a second significant positive relationship was determined to be between age and Myers Briggs personality types; Chi-Square $=22.90063$ ( $\mathrm{p} \geq .0429)$. Finally, a third positive relationship was uncovered between personality type (Myers Briggs) and gender; Chi-square $=22.90063$ ( $\mathrm{p} \geq$.0429) (see Tables 1, 2, and 3 below). 
TABLE 1

Chi-Square of number of dreams to dream types

\begin{tabular}{|c|c|c|c|}
\hline COUNT & \multicolumn{2}{|c|}{ DREAM TYPE } & $\underline{\text { ROW }}$ \\
\hline $\begin{array}{c}\text { Number of } \\
\text { Dreams }\end{array}$ & Archatype & Everyday & \\
\hline 0 & & 2 & $\begin{array}{c}2 \\
5.6\end{array}$ \\
\hline 1 & 1 & 2 & $\begin{array}{c}3 \\
8.3\end{array}$ \\
\hline 2 & & 4 & $\begin{array}{c}4 \\
11.1\end{array}$ \\
\hline 3 & 4 & 7 & $\begin{array}{c}11 \\
30.6\end{array}$ \\
\hline 4 & 5 & 2 & $\begin{array}{c}7 \\
19.4\end{array}$ \\
\hline 6 & 1 & $:$ & $\begin{array}{c}1 \\
2.8\end{array}$ \\
\hline 8 & 5 & ' & $\begin{array}{c}5 \\
13.9\end{array}$ \\
\hline 12 & 1 & & $\begin{array}{c}1 \\
2.8\end{array}$ \\
\hline 15 & 1 & & $\begin{array}{c}1 \\
2.8\end{array}$ \\
\hline 24 & 1 & & $\begin{array}{c}1 \\
2.8\end{array}$ \\
\hline $\begin{array}{l}\text { COLUMNY } \\
\text { TOTAS }\end{array}$ & $\begin{array}{c}19 \\
62.0\end{array}$ & $\begin{array}{c}17 \\
47.2\end{array}$ & $\begin{array}{c}36 \\
100.0\end{array}$ \\
\hline
\end{tabular}


TABLE 2

Chi-Square of Myers-Briggs to Age.

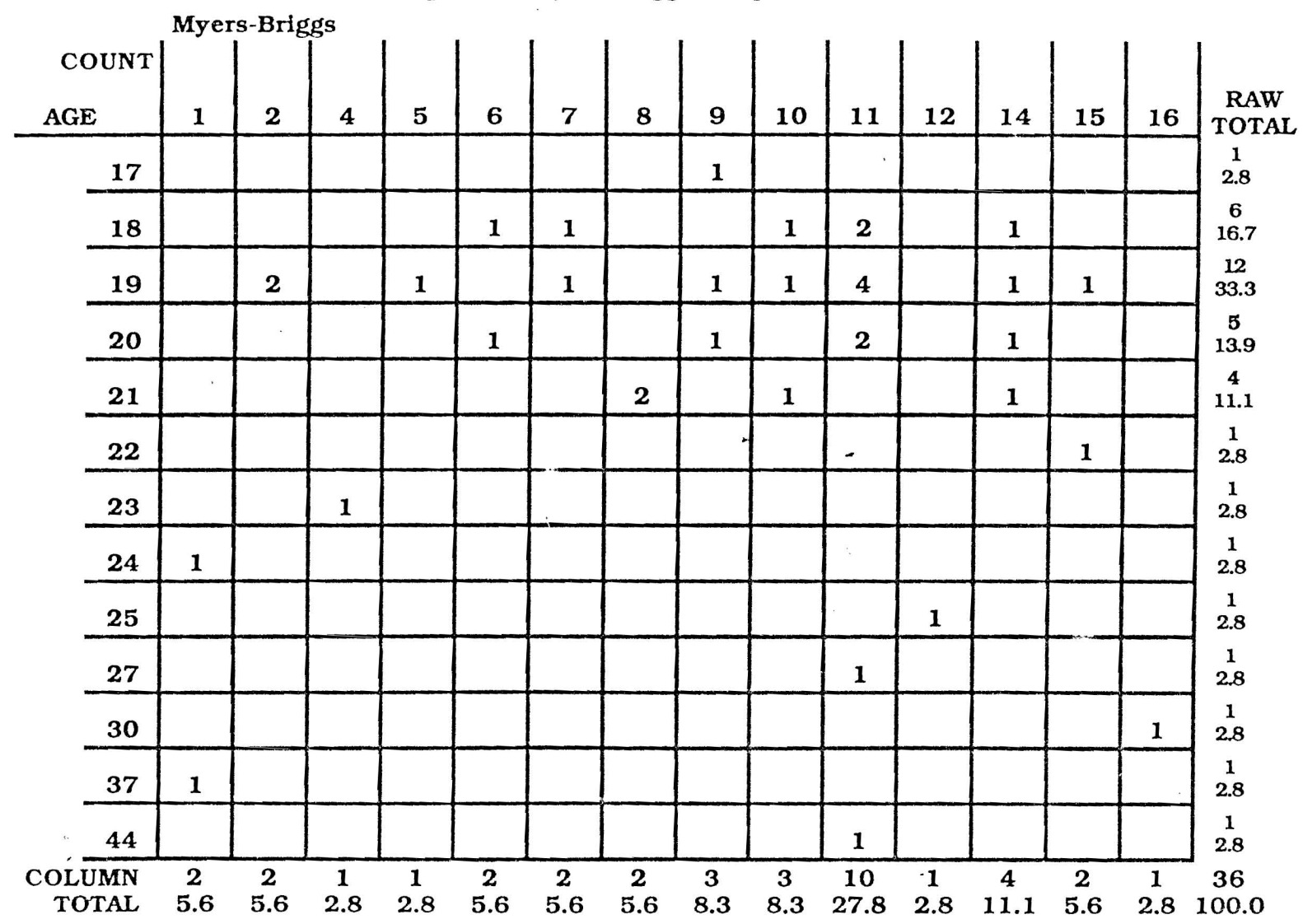

TABLE 3

Chi-Square of Myers-Briggs to sex

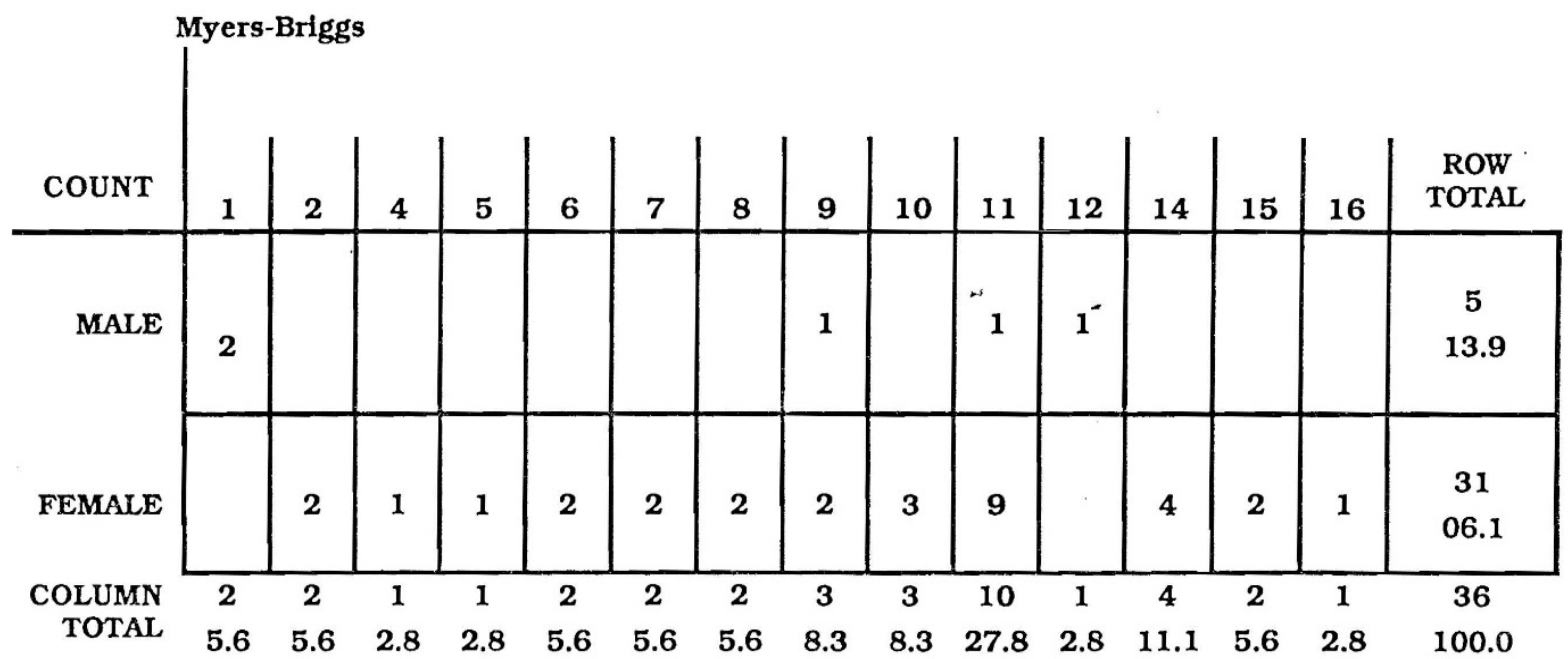

Also, the Myers-Briggs by sex was significant; Chi-square $=22.90063(\mathrm{p} \geq .0429)$. Using the statistics previously mentioned, the experimenters did not find any significant correlations between the Gordon Personality Profile Inventory (GPP-I) with any other group in the study. This confirms the reality of the Myers-Briggs as a Jungian based instrument and the GPP-I as not. 


\section{DISCUSSION}

The relationship between the Myers-Briggs Personality types and Dream types was interesting. Archetypical dreams were found more often in Myers-Briggs introverted personality types; those who rated high having an extroverted personality were found to have more everyday dreams.

A possible reason for these results are that extroverted individuals are more actively participating in the physical world around them as compared to introverted individuals. Therefore, introverts dreams would deal with those issues requiring introspection and philosophical content, which extroverted personality types deal with during their walking hours. Thus the introverted personality types are utilizing their dream world to analyze their everyday world. As earlier stated in this paper, Cann and Donderi (1986), found similar relationships.

The $56 \%$ of variables not accounted for in the Pearson correlation are due to unknown variables. The stress of school could be a factor in the results. Further studies focused on this factor or similar age/station stresses (isolation, relationships, residence, extra-curricular activities, etc.) would be of interest to dream researchers.

In future research, there should be a larger sample size and a control group. Also, subjects from the general population and other specific populations should be studied. Non-Caucasian population should be a particular focus on campuses, since gender proved a significant factor in the present study.

The finding that older subjects dream more often may be due to more stress, as a direct result of marriage, children, and employment as opposed to the younger subjects. A possible reason for this interesting dreaming difference could be that they utilize their dreams as a method of dealing with stress and problem solving. A larger number of subjects would improve future research, in that it would enable stronger statistical analysis and increased number of statistics. A more varied population would also further the same end.

The results of the Chi-square analyses clearly shows that sex and age have a distinct effect on the person's life history and personality development, as Kluger (1975) also found. This would make sense from a Jungian perspective, in that he believed that both genetics (collective unconscious) and learning history and serendipitous events (personal unconscious) determines personality.

The number of dreams to dream type, archetypical or every day, supports the Jungian theory, Cann and Donderi (1986) discussed. This present result is both Jungian supportive but also reflects what modern dream researchers find; that everyday dreams are more often seen in those actively involved in life and learning (Rock, 2004).

In conclusion, the present author's results supported the concept of compensation by Jung; the notion of an impelling equilibrium between contradicting mental elements. The previously stated suggestions for future research would improve the significance of the findings, namely; a larger subject group, a group outside a university setting, varying ages and an equal division of gender, and inclusion of non-Caucasian participants would increase the external validity and may lead to some interesting new information.

\section{References}

Cann, Douglas R. and Donderi, D. C. (1986). "Jungian Personality Typology and the recall of Everyday and Archetypal Dreams." Journal of Personality and Social Psychology, 50 (5), 1021-1029 


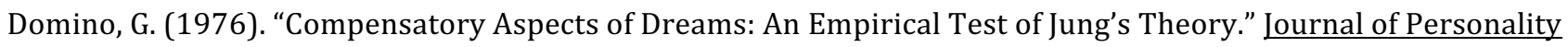
and Social Psychology, $\underline{34}$ (4), 658-662

Kluger, H. Y. (1975). “Archetypical Dreams and 'Everyday’ Dreams: A statistical Investigation into Jung's Theory of the Collective Unconsciousness", Israel Annals of Psychiatry and Related Disciplines, 13, 6-47.

Rock, A (2004). The Mind at Night: The New Science of How and Why We Dream. NY: Basic Books.

\section{APPENDIX A \\ PEARLMAN DREAM TECHNIQUES}

Step 1. Summary of the Dream-Symbols

Step 2. Fairy Tale: Chapter 1, Chapter 2

Step 3. Early Childhood Memory

Step 4. Recent Memory

Step 5. Life Meaning

Reasons for each segment:

- Story

- Symbols

- Fairy Tale

- Early Childhood Memory

- Recent Memory

- Persona of Each Actor

- Acting It Out

- Life Meaning 
APPENDIX B

JUNGIAN ARCHETYPAL ANALYSIS

$\underline{\text { Ten Most Admired Men }}$

Ten Most Admired Women
Characteristics

Characteristics
Archetype

Archetype 


\section{APPENDIX C MYERS-BRIGGS TYPE}

Introverts actions. protests or

\section{ISTP $=5$}

Cool onlookers-quiet, reserved, observing and analyzing life with detached curiosity and unexpected flashes of original humor. Usually interested in cause and effect, how and why mechanical things work, and in organizing facts using logical principles.

\section{$\mathrm{ISFJ}=2$}

Quiet, friendly, responsible, and conscientious. Work devotedly to meet their obligations. Lend stability to any project or group. Through, painstaking, accurate. Their interests are usually not technical. Can be patient with necessary details. Loyal, considerate, perceptive, concerned with how other people feel.

\section{ISFP $=6$}

Retiring, quietly friendly, sensitive, kind, modest about their abilities. Shun

disagreements, do not force their opinions or values on others. Usually do not care to lead but are often loyal followers. Often relaxed about getting things done, because they enjoy the present moment and do not want to spoil it by undue haste or exertion.

\section{ESTP $=9$}

Good at on-the-spot problem solving. Do not worry, enjoy whatever comes along. Tend to like mechanical things and sports, with friends on the side. Adaptable, tolerant, generally conservative in values. Dislike long explanations. Are best with real things that can be worked, handled, taken apart or put together.
Extroverts

\section{ESTJ $=13$}

Practical, realistic, matter-of-fact, with a natural head for business or mechanics. Not interested in subjects they see no use for, but can apply themselves when necessary. Like to organize and run activities. May make good administrators, especially if they remember to consider others feelings and points of view.

\section{$\mathrm{ESFP}=10$}

Outgoing, easygoing, accepting, friendly, enjoy everything and make things more fun for others by their enjoyment. Like sports and making things happen, Know what's going on and join in eagerly. Find remembering facts easier than mastering theories. Are best in situations that need sound common sense and practical ability with people as well as with things.

\section{Warm-hearted, talkative} popular, conscientious, born cooperators, active committee members. Need harmony and may be good at creating it. Always doing something nice for someone. Work best with encouragement and praise. Main interest is in things that directly and visibly affect people's lives.

\section{Intuitive Types \\ INJF=3}

Succeed by perseverance, originality, and desire to do whatever is needed or wanted. Put their best efforts into their work. Quietly forceful, conscientious, concerned for others. Respected for their firm principles. Likely to be honored and followed for their clear convictions as to how best to serve the common good.

\section{INFP=7}

Full of enthusiasms and loyalties, but seldom talk of these until they know you well Care about learning, ideas, language, and independent projects of their own. Tend to undertake too much, then somehow get it done. Friendly, but often too absorbed in what they are doing to be sociable Little Concerned with Possessions or physical surroundings.

$\mathrm{ENFP}=11$

Warmly enthusiastic, highspirited, ingenious, imaginative. Able to do almost anything that interests them. Quick with a solution for any difficulty and ready to help anyone with a problem. Often rely on their ability to improvise instead of preparing in advice. Can usually find compelling reasons for whatever they want.

\section{$\mathrm{ENFJ}=15$}

Responsive and responsible. Generally feel real concern for what others think or want, and try to handle things with due regard for the other person's feelings. Can present a proposal or lead a group discussion with ease and tact. Sociable, popular, sympathetic. Responsive to praise and criticism.
Usually have original minds and great drive for their own ideas and purposes. In fields that appeal to them, they have a fine power to organize a job and carry it through with or without help. Skeptical, critical, independent, determined, sometimes stubborn. Must learn to yield less important points in order to win the most important.

$$
\text { INTP=8 }
$$

Quiet and reserved. Especially enjoy theoretical or scientific pursuits. Like solving problems with logic and analysis. Usually interested mainly in ideas, with little liking for parties or small talk. Tend to have sharply defined interest. Need careers where some strong interest can be used and useful.

\section{ENTP $=12$}

Quick, ingenious, good at many things. Stimulating company, alert and outspoken. May argue for fun on either side of a question. Resourceful in solving new and challenging problems, but may neglect routine assignments. Apt to turn to one new interest after another skillful in finding logical reasons for what they want.

\section{Extroverts}

\section{$\mathrm{ENTJ}=16$}

Hearty, frank, decisive, leaders in activities. Usually good in anything that requires reasoning and intelligent talk, such as public speaking. Are usually well informed and enjoy adding to their fund of knowledge. may sometimes appear more positive and confident than their experience in an area warrents. 